\title{
Pediatric papillary thyroid cancer: current management challenges
}

This article was published in the following Dove Press journal:

OncoTargets and Therapy

28 December 2016

Number of times this article has been viewed

\author{
Frederik A Verburg' \\ Hanneke MVan Santen ${ }^{2}$ \\ Markus Luster' \\ 'University Hospital Gießen and \\ Marburg, Department of Nuclear \\ Medicine, Marburg, Germany; \\ ${ }^{2}$ University Medical Center Utrecht, \\ Wilhelmina Children's Hospital, \\ Utrecht, the Netherlands
}

\begin{abstract}
Although with a standardized incidence of 0.54 cases per 100,000 persons, differentiated thyroid cancer (DTC) is a rare disease in children and adolescents, it nonetheless concerns $\sim 1.4 \%$ of all pediatric malignancies. Furthermore, its incidence is rising. Due to the rarity and long survival of pediatric DTC patients, in most areas of treatment little evidence exists. Treatment of pediatric DTC is therefore littered with controversies, many questions therefore remain open regarding the optimal management of pediatric papillary thyroid cancer (PTC), and many challenges remain unsolved. In the present review, we aim to provide an overview of these challenging areas of patient and disease management in pediatric PTC patients. Data on diagnosis, surgery, radionuclide, and endocrine therapy are discussed, and the controversies therein are highlighted.
\end{abstract}

Keywords: pediatric cancer, papillary thyroid cancer, survival, I-131 therapy, follow-up, treatment

\section{Introduction}

Although with a standardized incidence of 0.54 cases per 100,000 persons, ${ }^{1}$ differentiated thyroid cancer (DTC) is a rare disease in children and adolescents; it nonetheless concerns $\sim 1.4 \%$ of all pediatric malignancies. Furthermore, its incidence is rising. ${ }^{2}$ In children and adolescents, DTC almost exclusively manifests in the form of papillary thyroid cancer (PTC).

Pediatric PTC shows no relationship with gender in prepubertal children. However, with increasing age, the incidence of PTC also increases, especially in young female adolescents. ${ }^{2,3}$ In the case of DTC diagnosis, these patients more or less exclusively present with a well-differentiated PTC.

Compared to adults, children more often present with lymph node and/or disseminated (so-called miliary) lung metastases. The latter usually only becomes apparent after radioactive iodine (RAI), as they are usually not visible when morphologic imaging techniques such as X-ray or computed tomography (CT) are used. Fortunately, in these young patients, PTC is almost guaranteed to show an avid uptake of RAI. As a result, prognosis in the pediatric PTC population is excellent when appropriate treatment is administered.

As pediatric PTC is a comparatively rare disease, most treatment concepts for this patient population are derived from experiences in the adult PTC population. While not necessarily false, these adaptations are often based on empiric derivation rather than on a solid basis of evidence - as there is little, if any, of the latter in the literature. Considering the lack of especially prospective therapy studies in pediatric PTC patients, it can be challenging to determine what exactly constitutes the appropriate treatment. The rarity of pediatric PTC as well as on the whole very good prognosis, combined with the ethical
Correspondence: Frederik A Verburg University Hospital Marburg, Department of Nuclear Medicine, Baldingerstraße, 35043 Marburg, Germany

Tel +49 642I 5862815

Email frederik.verburg@staff.unimarburg.de
OncoTargets and Therapy 2017:10 165-175

(c) (1) (2) ( 2017 Verburg et al. This work is published and licensed by Dove Medical Press Limited. The full terms of this license are available at https:/www.dovepress.com/terms.php

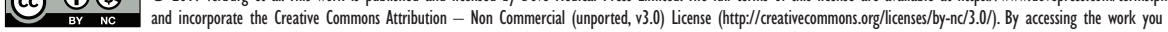
hereby accept the Terms. Non-commercial uses of the work are permitted without any further permission from Dove Medical Press Limited, provided the work is properly attributed. For peminsion for commercial use of this work, please see paragraphs 4.2 and 5 of our Terms (https://www.doveperess.com/terms.php). 
concerns surrounding medical trials in such a population of underage patients, makes prospective studies difficult.

Many questions, therefore, remain open regarding the optimal management of pediatric PTC, and many challenges remain unsolved. In the present review, we aimed to provide an overview of these challenging areas of patient and disease management in pediatric PTC patients.

\section{Diagnosis}

Most patients with pediatric PTC will be diagnosed because of specific symptoms, such as a growing thyroidal nodule or a persistent lymph node in the neck. Diagnostic procedures include palpation, thyroid ultrasound, fine-needle biopsy, and if need be, diagnostic hemithyroidectomy. In children, thyroid scintigraphy, especially in patients with normal or elevated thyroid-stimulating hormone (TSH), has no further role in elucidating the nature of a thyroid nodule. For more details on the diagnostic procedure of potential thyroid cancer lesions in children, we refer to relevant guideline documents such as those produced by the American Thyroid Association., ${ }^{4,5}$

Screening for PTC in children at risk, such as children with cancer predisposition syndromes (eg, Cowden) or after exposure to ionizing radiation, is an issue of debate. All in all, pediatric PTC has a very low to absent mortality. Treatment-related morbidity may be influenced by the stage of disease, however, as it was shown that there is some evidence in the literature that earlier detection of disease may benefit the patient in terms of reduced treatment-related morbidity. ${ }^{6}$ Despite these facts, screening for pediatric PTC in asymptomatic patients not at risk will not be effective in terms of either costs or the balance between true- and falsepositive test results. For patients who are at an increased risk, such as those who received prior radiation therapy to the thorax, neck, or head areas for other childhood cancers, a regular examination of the thyroid can be considered. This can either be done by palpation followed by ultrasound on indication or directly by ultrasound. The former strategy will be more specific than the latter, with fewer false-positive results. However, the latter strategy will be more sensitive and will result in fewer missed cancer cases or in the earlier detection of cancer cases which might limit treatment-related morbidity. ${ }^{6}$ Which of these strategies will be followed will be a matter of discussion between physician and patient as well the availability of specialized thyroid sonographers with pediatric experience. On the issue of screening children at risk of DTC after treatment of childhood cancer, a guideline will be forthcoming from the International Guideline Harmonization Group on late effects of childhood cancer.

\section{Treatment of pediatric DTC Surgery}

Whereas in adult patients, those with a primary tumor diameter $\leq 1 \mathrm{~cm}$ without any metastases are considered very low-risk cases for which a hemithyroidectomy is deemed to suffice, in children this is less clear. Especially in smaller children, a tumor of $1 \mathrm{~cm}$ diameter will take up a sizeable part of the patients' thyroid. However, unlike in adults, where there are several studies available that detail the risk of advanced disease features as a function of the tumor diameter (and show that the risk of these starts rising from a tumor diameter of $>1 \mathrm{~cm}$ ), ${ }^{7,8}$ such data are not available in children. Some prognostic data are available for children who only underwent hemithyroidectomy for pediatric PTC: it turned out that not having total thyroidectomy was one of the greatest risk factors for developing recurrent disease. ${ }^{9,10}$ Therefore, it has in recent years been without question that every pediatric PTC case warrants total thyroidectomy and, if possible, surgical resection of any involved lymph nodes. ${ }^{1,11,12}$ It is not impossible that this assumption may turn out to be slightly more strict than necessary in the future. The most recent trend in adult patients as seen in the 2015 American Thyroid Association guidelines on thyroid cancer management ${ }^{5}$ is that in selected cases a hemithyroidectomy is considered to suffice even for those with a $4 \mathrm{~cm}$ diameter tumor and lobectomy may be considered for tumors $<1 \mathrm{~cm}$. Without any prospective evidence to back this up, such a non-evidence-based change of management is likely not advisable for pediatric PTC patients at the moment.

The other surgical issue of debate is whether to perform a central compartment lymph node dissection, which is associated with an increased risk of hypoparathyroidism. These risks should be weighed against the risk for progressive disease.

In contrast to such challenges, it is comparatively clear that thyroid surgery is best performed by an experienced thyroid surgeon in order to minimize the risks of permanent hypoparathyroidism and that neural monitoring of the recurrent laryngeal nerve should be used to reduce the risk of permanent vocal cord paralysis. ${ }^{13-15}$

\section{|-I3| therapy}

The indications for adjuvant post-operative iodine-131 (I-131) therapy are a subject of debate, especially for pediatric PTC patients without lymph node or distant metastases ${ }^{12}-$ it has not been cleared beyond a doubt whether RAI will improve survival and/or reduce recurrence rates in these patients. In contrast, in patients with lymph node and/or distant 
metastases, there is abundant evidence to show that at least disease-free survival is improved by I-131 therapy. ${ }^{11,16}$

As thus far no prospective studies in pediatric PTC patients focusing on long-term recurrence and survival have been conducted, the precise identification of which patients should receive I-131 therapy will remain a subject of debate and controversy.

\section{I-I3I activity selection strategies}

No evidence is available in the literature on which I-131 activities are required for adjuvant post-operative I-131 therapy in pediatric PTC. Limited evidence, however, shows that lower activities are associated with a lower rate of successful I-131 ablation in pediatric PTC patients. ${ }^{17}$ Usually an empirically derived, fixed activity is used which is repeated as deemed necessary. The level of this activity may be tied to the patients' disease stage and should optimally be adjusted for body weight - at least in pre-adolescent children. Alternatively, a dosimetric strategy is used. Here, the patients' individual iodine biokinetics are determined to calculate the activity which will be administered for therapy.

In I-131 therapy of pediatric PTC, several parameters are at least equally or even more important than the administered activity for the radiation absorbed dose to tumor lesions, such as I-131 avidity of tumor tissue, residence time of I-131, the effective I-131 half life, and tumor size and shape. ${ }^{18}$ As all these parameters are highly individually variable, ${ }^{18}$ this fundamentally questions the feasibility of the quest for the single "best" therapeutic I-131 activity.

Furthermore, multiple administrations of lower fixed activities in what, in analogy to radiation therapy, can be considered a "fractionated" therapy may lead to changes in PTC biokinetics. Samuel et $\mathrm{al}^{19}$ showed that the uptake and consequently the lesion absorbed dose to the target tissue per given I-131 activity is reduced in subsequent therapies. This is best explained by the hypothesis that the least radioiodine avid cells are more likely to survive when an I-131 therapy course with a non-maximized activity is given. This in turn causes a sequential loss of therapeutic efficacy in the course of multiple courses of fixed activity I-131 therapy. Furthermore, it cannot be excluded that such a strategy potentially induces de-differentiation of the tumor by selective survival of undifferentiated cells. From this it follows that the administration of a single, high I-131 activity is likely more effective than the same cumulative activity given over multiple courses of I-131 therapy. This hypothesis was supported by a study by Klubo-Gwiezdzinska et $\mathrm{al}^{20}$ who showed that in adult high-risk patients, dosimetry-guided RAI resulted in a significantly better progression-free and disease-specific survival than in patients receiving fixed activities.

\section{Dosimetry}

In order to address these concerns, two dosimetry-based approaches have been developed. The first approach, developed by Benua et al, ${ }^{21,22}$ aimed to determine the activity that is as high as safely administrable (AHASA) thus targeting safety. Limit the absorbed dose to the blood to 2 Gy and the whole body activity in RAI in adults to $80 \mathrm{mCi}$ or $3 \mathrm{GBq}$ I-131 at 48 hours after the administration: this should avoid severe damage to the hematopoietic system as well as pneumonitis or pulmonary fibrosis, respectively. The latter was confirmed by later studies from other groups which shows that AHASA-based concepts are safe and are potentially more efficacious than fixed activity ones. ${ }^{20,23}$

In the second approach, Maxon et $\mathrm{al}^{24}$ were targeting efficacy. Therefore, they first determined the activity that is as low as reasonably achievable while delivering a desired radiation absorbed dose to tumor lesions. Maxon et $\mathrm{al}^{24,25}$ first aimed at a specified radiation absorbed dose to the target tissue, namely, 300 Gy to thyroid remnants and 80 Gy for the treatment of cervical lymph node metastases. More recent studies based on measurements with improved equipment (positron emission tomography [PET]/CT) and more suitable tracers for lesion dosimetry (I-124) support the hypothesis that therapeutic outcome correlates with the absorbed dose administered to the target tissue. ${ }^{26-28}$

Although we refer to other literature for technical details, ${ }^{29,30}$ briefly summarized, in both approaches, dosimetry is performed prior to I-131 therapy by measuring the radioiodine kinetics in the patient after administration of a very small radioiodine activity $(<10-15 \mathrm{MBq}$ in order to prevent a possible stunning ${ }^{31,32}$ ). Either I-131 or I-124 can be used for the assessment. I-124 offers the advantage of better imaging through PET and allows a much more accurate lesion dosimetry. However, I-131 is used more frequently as it is ubiquitously available and comparatively affordable.

The patients' metabolic state (ie, hypo- or euthyroidism) needs to be the same during dosimetry and therapy, while the metabolic state will affect kidney function, thus the I-131 clearance rate and consequently the whole body I-131 residence time. Also, the level of TSH will influence the uptake of the radiopharmaceutical in the thyroid cells. Therefore, in patients who are treated under levothyroxine (LT4) withdrawal conditions, dosimetry should be performed under LT4 withdrawal as well. In patients treated with recombinant human TSH (on a compassionate use basis), 
dosimetry should be performed in a euthyroid state, that is, during LT4 therapy.

Some limits apply to the application of dosimetric concepts as detailed earlier. The AHASA limit of 2 Gy is based on few cases of severe bone marrow suppression in adults. ${ }^{21}$ A later study targeting at 3-Gy red marrow dose ${ }^{26}$ and the observation in another study that older patients treated with fixed activities of 7.4 or $11.1 \mathrm{GBq}$, who frequently exceed Benua's safety limit, ${ }^{33,34}$ do not show corresponding severe hematotoxic reactions indicate that the limit of 2 Gy might be regarded as conservative. However, in the absence of more extensive hard scientific evidence on the safety of higher limits, it appears eminently sensible to maintain an upper safety limit of $2 \mathrm{~Gy}$.

Another limitation that must be considered relevant for pediatric PTC patients is that the second dosimetric safety limit of no $>80 \mathrm{mCi}$ or $3 \mathrm{GBq}$ I-131 retained whole body activity 48 hours after I-131 application was determined for adults. This limit was established based on the total body mass in normal non-obese adult individuals..$^{35,36}$ In pediatric patients, these limits likely must be adapted to account for the smaller lungs (and consequently lower total mass of the lungs) of pediatric patients. Furthermore, lung dosimetry (preferably three dimensional (3D)) is indicated in children with high I-131 uptake in disseminated lung metastases. $^{37-39}$

The question which pediatric PTC patients will in the end benefit from a dosimetric approach to I-131 therapy is a difficult one. Here we also refer to an extensive treatise on this topic. ${ }^{40}$ Briefly summarized, the more advanced a pediatric PTC case is, the more the benefits of the dosimetric approach to I-131 therapy appear to outweigh the extra effort, costs, and potential side effects.

\section{rhTSH stimulation}

High thyrotropin levels ( $>30 \mathrm{mU} / \mathrm{L}$ ) have generally been considered necessary for I-131 ablation and therapy of both benign post-surgical thyroid remnants and DTC metastases in order to induce sufficient I-131 uptake, ${ }^{41-43}$ although recent new evidence is questioning this notion. ${ }^{44}$ Such high TSH levels can be achieved either by LT4 withdrawal for 3-4 weeks, or by intramuscular injection of rhTSH. As hypothyroidism is avoided, the use of rhTSH results in an unimpaired quality of life. ${ }^{45-47}$ A further advantage of rhTSH is that there is a lower radiation exposure to the rest of the body, including the bone marrow, ${ }^{18}$ the reproductive system, and the salivary glands ${ }^{48,49}$ because of faster peripheral I-131 clearance due to the euthyroid peripheral metabolic state.
Over time, many studies have shown the equivalence of rhTSH and LT4 withdrawal for both TSH-stimulated thyroglobulin (Tg) testing, with or without concurrent dxWBS ${ }^{50}$ and for initial post-operative I-131 ablation or adjuvant I-131 therapy. ${ }^{51-53}$ However, there are few prospective studies in the literature in which LT4 withdrawal and rhTSH were compared for the treatment of DTC metastases. The limited body of evidence that is available appears to indicate that rhTSH does not result in an equally high radiation absorbed dose to the tumor. Therefore, the use of rhTSH in I-131 therapy of patients with persistent local or metastatic DTC remains a form of off-label use, which should only be opted for with all the due caution that is required in such situations.

Also, for the pediatric population, this preparation is not registered and has not been formally tested for safety and efficacy. As pediatric PTC if anything is likely more responsive to TSH stimulation than the adult variety, the efficacy, as shown by several reported pediatric series treated at least in part with rhTSH, may, however, not pose a problem. As for safety, there are still no reports of serious side effects from rhTSH occurring in pediatric patients in spite of rhTSH being used in such patients on an off-label use base around the world on a daily basis.

\section{Low iodine diet}

In pharmacological terms, stable iodine is a competitive inhibitor of I-131. High concentrations of stable iodine would thus inhibit I-131 uptake. Numerous studies have demonstrated that a low iodine diet for $\sim 2$ weeks prior to I-131 ablation is effective for lowering the concentration of stable iodine in the blood, increasing I-131 uptake in thyroid remnants and metastases, and thus increasing the success rate of I-131 ablation. ${ }^{54-58}$

Consequently, a low-iodine diet is recommended for about 2 weeks prior to I-131 administration in order to maximize treatment efficacy.

\section{Short-term side effects of $|-| 3 \mid$ treatment}

Radioiodine therapy is mostly well tolerated; however, as I-131 is physiologically taken up by both benign and malignant thyroid tissues and by several other structures such as the salivary glands or the stomach lining, immediate side effects due to high I-131 exposure may occur. These include local pain in the former thyroid region as a sign of radiation thyroiditis. In practice, this side effect is easily treated with light analgetic medication such as paracetamol and locally applied ice packs. Furthermore, radiation gastritis might cause nausea or more rarely vomiting, which however reacts 
well to anti-emetic medication such as ondansetron. Last but not least, the radiation sialadenitis may cause both pain in the salivary glands and short-term changes of taste. As damage to the salivary glands can greatly affect the quality of life, the prevention of it has been a topic of research for quite some time.

\section{Prevention of salivary gland damage}

One of the most frequent long-term complications of I-131 therapy in children and adults is the occurrence of salivary gland damage. As the salivary glands physiologically take up I-131, in some patients this causes a sufficient irradiation of the salivary glands to cause permanent dysfunction. This results in a permanent xerostomia (dry mouth), which is a major impairment of the patients' quality of life.

Attempts have been made to medically protect the salivary glands during I-131 therapy in adult patients by the intravenous administration of $500 \mathrm{mg} / \mathrm{m}^{2} \mathrm{~S}-2$-(3-aminopropylamino)ethylphosphorothioic acid (amifostine) prior to I-131 therapy. In a double-blinded trial, the administration of amifostine caused an unchanged salivary gland function compared to the pre-therapeutic situation. In contrast, patients who did not receive amifostine showed a highly significant reduction of the salivary gland function. ${ }^{59}$ Treatment with a lower dose of $300 \mathrm{mg} / \mathrm{m}^{2}$ was shown not to be effective. ${ }^{60}$ However, amifostine protection has not been explored further; a likely explanation of this lies in the potential side effects of the substance.

Traditionally, stimulation of the salivary glands using, for example, lemon drops and/or chewing gum, was thought to lead to a lower radiation exposure through an increased washout of I-131. However, several recent studies have shown that when applied immediately after I-131 administration this may actually lead to an increased radiation exposure through an increase in blood flow to the salivary glands which results in an increased I-131 uptake. ${ }^{61}$ There is some evidence that delaying the start of stimulation by at least 24 hours after I-131 administration may lead to a lower rate of salivary gland dysfunction. ${ }^{62}$ Again these data were only obtained in adult patients; similar studies in children are completely lacking.

\section{TSH suppressive therapy}

As in any post-thyroidectomy patient, the postoperative life-long administration of LT4 is obligatory in pediatric PTC patients. ${ }^{63}$ Whether this should be substitution or TSH suppressive therapy is still a matter of debate among professionals.
The goal for thyroid hormone substitution in all children treated for DTC is achieving an adequate substitution dose for optimal growth and development. Within this assumption, for different patient groups within the pediatric DTC (pedDTC) population, additional different goals of thyroid hormone therapy apply. TSH is a stimulating factor for both normal and malignant thyrocytes. It is therefore not surprising that generally higher TSH concentrations at diagnosis are associated with a more advanced tumor. ${ }^{64}$ Thus, TSH suppressive therapy will at least in theory reduce the risk and rate of tumor progression.

Unfortunately, TSH suppression is a non-physiological hyperthyroid state, which in older patients is associated with complications such as an increased loss of bone mass or potential cardiac complications. ${ }^{65-67}$ In younger patients, especially in pediatric PTC patients, these effects are not as well studied. Next to bone and cardiac effects, another possible adverse effect of a chronic thyreotoxic state with suppressed concentrations of TSH during childhood may be an accelerated bone maturation resulting in a decreased final height. Although anecdotal evidence among colleagues also describes patients suffering from a loss in scholastic achievement after introduction of TSH suppressive therapy, this may be difficult to separate from the general psychooncological problems related to a cancer diagnosis at a juvenile age and no good evidence exists either for or against this possible phenomenon.

For patients without evidence of remaining disease after therapy, studies have shown that median TSH concentrations $<2 \mathrm{mU} / \mathrm{L}$ are not associated with increased rates of recurrence or DTC-related death. ${ }^{68,69}$ However, patients with a higher median TSH concentration are at greater risk of DTC recurrence.

In adults with proven persistent and/or metastatic disease, there is a benefit of TSH-suppressive therapy: it will lead to a lower DTC-related death rate at least in older adults. ${ }^{70}$ In pediatric PTC patients, no such survival benefit has thus far been shown. However, it has been shown that pediatric PTC patients who do not or insufficiently respond to I-131 therapy will still do very well: multiple studies have provided evidence of remission of disease over the course of follow-up under TSH suppressive therapy only.

It might therefore be argued that TSH suppressive therapy should be initiated in all patients who receive total thyroidectomy and I-131 ablation/adjuvant therapy and be maintained for the first year after therapy (or shorter if a disease free status is proven before the first year is over). After this first year, due to the aforementioned negative effects of 
TSH suppressive therapy, any proven disease-free patient should be switched to LT4 replacement therapy aiming at non-suppressed TSH concentrations in the lower half of the normal range.

The management of pediatric PTC patients with uncertain disease-free status (ie, "no structural evidence of disease") is more difficult. Whereas these patients are not for sure completely free of any detectable sign of disease, the prognostic relevance of such findings is unclear. As there is a distinct lack of evidence in the literature to guide decisions here, the attending physician will need to decide in conjunction with the patient in question.

However, in those in whom it is warranted, that is, those patients with unequivocal evidence of remaining disease and/or increasing Tg levels, especially when no longer responding to I-131 therapy, TSH suppression will still remain a life-long balancing act. In most patients, TSH levels can be suppressed without clinical hyperthyroidism. Usually this state is associated with peripheral triiodothyronine levels within the normal range. As there is no evidence to support a further benefit for patients resulting from suppressing TSH levels to levels $<0.1 \mathrm{mU} / \mathrm{L}$, it could be considered adequate to aim for TSH levels which do not exceed this level. ${ }^{70}$

\section{Advanced disease}

Although pediatric PTC patients can present with very advanced, highly metastasized disease at initial presentation, these patients almost without exception will respond very well to total thyroidectomy with lymph node dissection followed by I-131 therapy.

\section{|-|3| responsive advanced disease}

Conventionally, it is considered the best strategy to continue I-131 therapy in the form of repeated courses until either a complete biochemical/clinical response is seen or no further response to the previous cycle can be objectified.

However, evidence is emerging that even in patients who no longer appear to respond to I-131 therapy, the effects of this therapeutic modality may show many years after. In such patients, a long time after the last course of I-131 therapy further signs of disease remission such as reduced I-131 uptake on diagnostic whole body scintigraphy or a further reduction of Tg levels are seen. ${ }^{71}$ Likely these effects are at least in part attributable to continuous TSH suppression in these patients.

\section{Harmful effects of I- I 3 I}

The risk of malignancy due to I-131 therapy in pediatric PTC patients has not been clarified definitively. ${ }^{72-75}$ Also, further side effects of I-131 therapy such as xerostomia (prevalence range: $16 \%-54 \%),{ }^{76-78}$ lacrimal gland dysfunction (prevalence: $11 \%),{ }^{76,77}$ transient male gonadal dysfunction, ${ }^{72,79}$ or transient female gonadal ${ }^{72}$ dysfunction may occur. Data in children upon the late effects of I-131 are scarce and may be currently underestimated. The prevalence and severity of adverse effects seem to be correlated to the cumulative I-131 activity. These late effects can severely impact the quality of life. ${ }^{72}$ It is therefore important to properly select the treatment for pediatric PTC patients. These include the correct indication for and correct dosing of I-131 therapy. Overtreatment with the risk of causing more harm than good should be avoided according the old medical principle of "primum non nocere." It is well known that high I-131 activities may induce leukemia. This was already observed in some of the first DTC patients treated with I-131 therapy ${ }^{80}$ and has been confirmed in multiple subsequent reports. ${ }^{72,81}$ These reports included patients treated with low activities or multiple times within a short time frame. However, it could also be established that a more frequent radiation exposure or an exposure to higher cumulative doses will lead to a higher risk of complications. It is; however, unclear to what degree and at what point.

Furthermore, it was reported that the risk of second primary solid tumors could be elevated after I-131 therapy. ${ }^{82}$ Hay et $\mathrm{al}^{12}$ report a statistically significant excess mortality due to non-thyroid malignancies in survivors of pediatric PTC first occurring 30-50 years after diagnosis. However, as in the latter study, only a minority of patients received I-131 therapy, the excess mortality may be due to other, for example, genetic, causes.

In contrast with such negative reports, Reiners et al ${ }^{16}$ reported on the results of treatment from a large cohort of children and adolescents with high-risk radiation-induced PTC after the Chernobyl reactor meltdown. These children mostly received multiple courses of high body weightadapted activities (100 MBq/kg). The authors did, however, not observe secondary malignancies during a median of 11.3-years follow-up after the last RAI. ${ }^{16}$

As pediatric PTC patients have a long remaining life expectancy, the risk of developing secondary tumors over the course of a lifetime is non-negligible. This risk is related to the cumulative life time I-131 activity as well as to other, potentially predisposing, factors such as genetic ones. Furthermore, especially in patients with extensive lung metastases, the risk of pulmonary fibrosis which is also related to the cumulative radiation exposure needs to be considered as a rare but potentially lethal complication. Considering recent evidence that long-term prognosis in 
patients who do eventually become disease free does not markedly improve after $>4$ courses of I-131 therapy or a cumulative life time activity of $22 \mathrm{GBq}$ compared to those who never become disease free, the harms in the long term may outweigh the benefits. Therefore, for the future, it may be advisable in pediatric PTC patients to consider cessation of further I-131 therapy courses if a complete remission of disease is not achieved with 3-4 courses of I-131 therapy.

\section{Progressive advanced disease}

It is very rare for a pediatric PTC patient to become I-131 refractory to the point that this will include tumor progression under or shortly after I-131 therapy. Therefore, no evidence exists on how to proceed in such rare, unlucky individuals. While new substances from the multikinase inhibitor class have shown good results in the adult patient population with I-131 refractory disease, no studies are yet available in pediatric PTC patients.

\section{Open clinical questions and perspectives}

As described previously, many aspects of treatment of pedDTC patients are still a subject of debate mostly due to lack of evidence.

The matter of whether to use dosimetric RAI will in the end largely be determined by the attending physicians' preferences and experiences as well as the availability of experts in medical physics with knowledge of and experience with dosimetric RAI.

It is always possible to perform dosimetric RAI even in "simple" pediatric pedDTC cases in order to ensure standardized conditions and to maximize the chances of successful ablation. The blood absorbed dose not only is a surrogate for the dose to the red marrow but also closely reflects the true amount of I-131 available to the target tissue. ${ }^{83}$ In thyroid remnant ablation, it seems to correlate better with therapeutic success than the administered activity alone. ${ }^{84,85}$ Compared to the AHASA therapy strategy, much lower blood doses need to be aimed for. In adults, ablation was significantly more often successful in patients who achieved a blood dose of $\geq 350 \mathrm{mGy} .{ }^{84}$ In fact, in a collective of children treated with Chernobyl-related DTC, we were able to show that an increasing blood dose could compensate a higher tumor mass as indicated by the tumor-marker Tg. These findings suggest a new indication for dosimetric ablative RAI, if they can be confirmed by prospective randomized studies.

Certainly, the limit of 2-Gy absorbed dose to the bone marrow has not been rigorously scientifically proven. Little is known about the applicability of this limit for a single RAI to children. In our experience, 2 Gy appears to be a safe limit. Even of more concern are the risks of cumulated doses from several therapies, raising the question of when to stop repeating RAI. Most physicians in the course of their career will encounter one or more pediatric patients who will appear RAI refractory, as Tg levels will no longer fall or diagnostic or post-therapeutic whole body scintigraphy do not improve further after multiple courses of RAI. Although one could consider repeating treatment as long as pathologic I-131 uptake is present, there is now a considerable body of evidence in the literature to support a restrained approach. Under stringent TSH suppressive LT4 therapy, these patients in multiple studies appear to enjoy a very good long-term prognosis with apparently spontaneous further remission occurring without further RAI. ${ }^{71,86}$ Therefore, we would advocate ceasing RAI once Tg levels fail to respond to RAI or no further remission of disease is observed on $\mathrm{dxWBS}$ or rxWBS whole body scintigraphy. Even stopping RAI at an even earlier time point in the course of pedDTC treatment may be justifiable as such patients have thus far fared well under TSH suppressive therapy alone. ${ }^{71,86}$

\section{Risk stratification and considerations for follow-up}

Many staging systems have been defined for DTC which all share the same aim: to provide an estimate of the risk of thyroid cancer-related death and, to a lesser extent, of disease recurrence based on the extent of disease at initial diagnosis.

Certainly some staging systems have been more successful than others; generally, however, the empirically defined tumor, lymph node, distant metastasis (TNM) system which was jointly developed by the Union International Contre le Cancer and the American Joint Committee on Cancer (UICC/AJCC) has found the broadest acceptance. ${ }^{87,88}$ While some staging systems do reasonably well at separating DTC patients in different risk groups for death, none have done well for predicting the risk of recurrence. Even a system which was dedicated to the prediction of recurrence, developed by the American Thyroid Association, had a proportion of variance explained (PVE) of only 34\% in a large DTC population. ${ }^{89}$

Recommendations for initial treatment necessarily have to be based on the known extent of disease at initial diagnosis, with microcarcinoma warranting a less aggressive treatment (ie, lobectomy) than low-risk carcinoma, which in turn warrants a less aggressive treatment than, for example, high-risk carcinomas - in the latter case one could, for example, consider increasing the I-131 activity given for post-surgical I-131 ablation.

It has, however, become clear in the past decade that "risk" of DTC-related death or recurrence is not a static variable. 
Especially the incorporation of the response to therapy, as assessed with sensitive $\mathrm{Tg}$ measurement, ultrasound and hybrid, 3D I-131 dxWBS with single-photon emission $\mathrm{CT} / \mathrm{CT}^{90}$ has brought new insights into the dynamically evolving risk profile of patients. It has become clear that a patient who is free of detectable disease by all the available sensitive diagnostic tools is likely truly disease-free: recurrence rates in patients who are disease-free after one course of I-131 ablation are in the range of $1 \%-3 \%$. Furthermore, in these patients, (nearly) all recurrences occur within the first 5 years after diagnosis. Also, the risk of recurrence is as high (or low) in patients who before initial therapy were considered to be at high risk for recurrence based on the extent of disease as it is in patients who were originally considered low risk. ${ }^{89,91}$ In older studies, late recurrences occurring $>20$ years after initial diagnosis have also been described - however, the patients reported here were treated in times before modern, highly sensitive Tg assays were available, and these late recurrences may therefore become exceedingly rare in the future.

Adding an assessment of the success of initial therapy to the existing ATA predictive system for recurrence may help to form follow-up recommendations, as was shown by Tuttle et al, ${ }^{89}$ with a dramatic increase in the explained proportion of variance to $84 \%$.

Of course, risk stratification is not a goal per se. The eventual goal of risk estimation is to separate those patients who require more intensive monitoring from those who can be put at ease and left to a less frequent and less intensive follow-up. Even though DTC has an inherently good prognosis, follow-up with TSH-stimulated Tg measurement and dxWBS still pose a considerable burden on the quality of life of patients. Such procedures should therefore be indicated with care and only in those patients who are likely to benefit from such relatively invasive follow-up procedures. Here a major difficulty is posed by a lack of consensus opinion in the literature on what constitutes "treatment success", also referred to as a "successful ablation".

In addition to discussions on the precise criteria to be used in the definition of treatment response, some authors have differentiated the response to treatment in "no evidence of disease" (including both imaging and Tg measurement), "no structural evidence of disease" (ie, detectable Tg but negative imaging), and "evidence of disease" (ie, positive imaging and/or pathological evidence).

\section{Conclusion}

Pediatric DTC behaves different than adult DTC and for this reason should be treated differently. Long-term follow-up studies of pediatric DTC cohorts are necessary to increase our current knowledge of clinical behavior of pediatric DTC, risk factors for recurrence, and late effects of the administered treatments. Prospective multicenter trials should be performed, preferably across borders in order to enable the inclusion of sufficient patient numbers to generate new data.

\section{Disclosure}

FAV has been a consultant for Bayer Healthcare and Sanofi-Genzyme and has received speaker honoraria from Diasorin and SanofiGenzyme. ML has been a consultant for AstraZeneca, Bayer Healthcare, SanofiGenzyme and Sobi and received speaker honoraria and research support from SanofiGenzyme, Henning and Merck. HVS reports no conflicts of interest in this work.

\section{References}

1. Rivkees SA, Mazzaferri EL, Verburg FA, et al. The treatment of differentiated thyroid cancer in children: emphasis on surgical approach and radioactive iodine therapy. Endocr Rev. 2011;32(6):798-826.

2. Hogan AR, Zhuge Y, Perez EA, Koniaris LG, Lew JI, Sola JE. Pediatric thyroid carcinoma: incidence and outcomes in 1753 patients. J Surg Res. 2009;156(1):167-172.

3. Demidchik YE, Saenko VA, Yamashita S. Childhood thyroid cancer in Belarus, Russia, and Ukraine after Chernobyl and at present. Arq Bras Endocrinol Metabol. 2007;51(5):748-762.

4. Francis GL, Waguespack SG, Bauer AJ, et al; American Thyroid Association Guidelines Task Force. Management guidelines for children with thyroid nodules and differentiated thyroid cancer. Thyroid. 2015; 25(7):716-759.

5. Haugen BR, Alexander EK, Bible KC, et al. 2015 American thyroid association management guidelines for adult patients with thyroid nodules and differentiated thyroid cancer: the American thyroid association guidelines task force on thyroid nodules and differentiated thyroid cancer. Thyroid. 2016;26(1):1-133.

6. Clement SC, Kremer LC, Links TP, et al. Is outcome of differentiated thyroid carcinoma influenced by tumor stage at diagnosis? Cancer Treat Rev. 2015;41(1):9-16.

7. Verburg FA, Mader U, Luster M, Reiners C. Primary tumour diameter as a risk factor for advanced disease features of differentiated thyroid carcinoma. Clin Endocrinol (Oxf). 2009;71(2):291-297.

8. Machens A, Holzhusen HJ, Dralle H. The prognostic value of primary tumor size in papillary and follicular thyroid carcinoma. A comparative analysis. Cancer. 2005;103(11):2269-2273.

9. Jarzab B, Handkiewicz JD, Wloch J, et al. Multivariate analysis of prognostic factors for differentiated thyroid carcinoma in children. Eur J Nucl Med. 2000;27(7):833-841.

10. Mihailovic J, Nikoletic K, Srbovan D. Recurrent disease in juvenile differentiated thyroid carcinoma: prognostic factors, treatments, and outcomes. J Nucl Med. 2014;55(5):710-717.

11. Handkiewicz-Junak D, Wloch J, Roskosz J, et al. Total thyroidectomy and adjuvant radioiodine treatment independently decrease locoregional recurrence risk in childhood and adolescent differentiated thyroid cancer. J Nucl Med. 2007;48(6):879-888.

12. Hay ID, Gonzalez-Losada T, Reinalda MS, Honetschlager JA, Richards ML, Thompson GB. Long-term outcome in 215 children and adolescents with papillary thyroid cancer treated during 1940 through 2008. World J Surg. 2010;34(6):1192-1202.

13. Dralle H, Sekulla C, Haerting J, et al. Risk factors of paralysis and functional outcome after recurrent laryngeal nerve monitoring in thyroid surgery. Surgery. 2004;136(6):1310-1322. 
14. Musholt TJ, Clerici T, Dralle H, et al; Interdisciplinary task force guidelines of the German Association of Endocrine Surgeons. German association of endocrine surgeons practice guidelines for the surgical treatment of benign thyroid disease. Langenbecks Arch Surg. 2011; 396(5):639-649.

15. Thomusch O, Machens A, Sekulla C, Ukkat J, Brauckhoff M, Dralle H The impact of surgical technique on postoperative hypoparathyroidism in bilateral thyroid surgery: a multivariate analysis of 5846 consecutive patients. Surgery. 2003;133(2):180-185.

16. Reiners C, Biko J, Haenscheid H, et al. Twenty-five years after chernobyl: outcome of radioiodine treatment in children and adolescents with very-high-risk radiation-induced differentiated thyroid carcinoma. J Clin Endocrinol Metab. 2013;98(7):3039-3048.

17. Verburg FA, Mader U, Luster M, Hanscheid H, Reiners C. Determinants of successful ablation and complete remission after total thyroidectomy and ${ }^{131}$ I therapy of paediatric differentiated thyroid cancer. Eur J Nucl Med Mol Imaging. 2015;42(9):1390-1398.

18. Hanscheid H, Lassmann M, Luster M, et al. Iodine biokinetics and dosimetry in radioiodine therapy of thyroid cancer: procedures and results of a prospective international controlled study of ablation after rhTSH or hormone withdrawal. J Nucl Med. 2006;47(4):648-654.

19. Samuel AM, Rajashekharrao B, Shah DH. Pulmonary metastases in children and adolescents with well-differentiated thyroid cancer. $J \mathrm{Nucl}$ Med. 1998;39(9):1531-1536.

20. Klubo-Gwiezdzinska J, Van Nostrand D, Atkins F, et al. Efficacy of dosimetric versus empiric prescribed activity of 131I for therapy of differentiated thyroid cancer. J Clin Endocrinol Metab. 2011;96(10): 3217-3225.

21. Benua RS, Cicale NR, Sonenberg M, Rawson RW. The relation of radioiodine dosimetry to results and complications in the treatment of metastatic thyroid cancer. Am J Roentgenol Radium Ther Nucl Med. 1962; 87:171-182.

22. Benua RS, Leeper RD. A method and rationale for treating metastatic thyroid carcinoma with the largest safe dose of I-131. In: MedeirosNeto G, Gaitan G, editors. Frontiers In Thyroidology. New York, NY: Plenum Medical Book Co; 1986:1317-1321.

23. Verburg FA, Hanscheid H, Biko J, et al. Dosimetry-guided high-activity (131)I therapy in patients with advanced differentiated thyroid carcinoma: initial experience. Eur J Nucl Med Mol Imaging. 2010;37(5): 896-903.

24. Maxon HR, Thomas SR, Hertzberg VS, et al. Relation between effective radiation dose and outcome of radioiodine therapy for thyroid cancer. N Engl J Med. 1983;309(16):937-941.

25. Maxon HR 3rd, Englaro EE, Thomas SR, et al. Radioiodine-131 therapy for well-differentiated thyroid cancer - a quantitative radiation dosimetric approach: outcome and validation in 85 patients. J Nucl Med. 1992; 33(6):1132-1136.

26. Dorn R, Kopp J, Vogt H, Heidenreich P, Carroll RG, Gulec SA. Dosimetry-guided radioactive iodine treatment in patients with metastatic differentiated thyroid cancer: largest safe dose using a risk-adapted approach. J Nucl Med. 2003;44(3):451-456.

27. Chiesa C, Castellani MR, Vellani C, et al. Individualized dosimetry in the management of metastatic differentiated thyroid cancer. $Q \mathrm{~J} \mathrm{Nucl}$ Med Mol Imaging. 2009;53(5):546-561.

28. Flux GD, Haq M, Chittenden SJ, et al. A dose-effect correlation for radioiodine ablation in differentiated thyroid cancer. Eur J Nucl Med Mol Imaging. 2010;37(2):270-275.

29. Lassmann M, Haenscheid H, Chiesa C, Hindorf C, Flux G, Luster M. EANM dosimetry committee series on standard operational procedures for pre-therapeutic dosimetry I: blood and bone marrow dosimetry in differentiated thyroid cancer therapy. Eur J Nucl Med Mol Imaging. 2008; 35(7):1405-1412.

30. Lassmann M, Hanscheid H, Verburg FA, Luster M. The use of dosimetry in the treatment of differentiated thyroid cancer. $Q \mathrm{~J} \mathrm{Nucl} \mathrm{Med} \mathrm{Mol}$ Imaging. 2011;55(2):107-115.

31. Lassmann M, Luster M, Hanscheid H, Reiners C. Impact of 131I diagnostic activities on the biokinetics of thyroid remnants. $\mathrm{J} \mathrm{Nucl} \mathrm{Med}$. 2004;45(4):619-625.
32. Verburg FA, Verkooijen RB, Stokkel MP, van Isselt JW. The success of 131I ablation in thyroid cancer patients is significantly reduced after a diagnostic activity of $40 \mathrm{MBq}$ 131I. Nuklearmedizin. 2009;48(4): $138-142$.

33. Tuttle RM, Leboeuf R, Robbins RJ, et al. Empiric radioactive iodine dosing regimens frequently exceed maximum tolerated activity levels in elderly patients with thyroid cancer. J Nucl Med. 2006;47(10): $1587-1591$

34. Kulkarni K, Van Nostrand D, Atkins F, Aiken M, Burman K, Wartofsky L. The relative frequency in which empiric dosages of radioiodine would potentially overtreat or undertreat patients who have metastatic welldifferentiated thyroid cancer. Thyroid. 2006;16(10):1019-1023.

35. ICRP. Basic Anatomical and physiological data for use in radiological protection: reference values. A report of age- and gender-related differences in the anatomical and physiological characteristics of reference individuals. ICRP Publication 89. Ann ICRP. 2002;32(3-4):5-265.

36. ICRP. Radiation dose to patients from radiopharmaceuticals. Addendum 3 to ICRP publication 53. ICRP publication 106. Approved by the Commission in October 2007. Ann ICRP. 2008;38(1-2):1-197.

37. Sgouros G, Song H, Ladenson PW, Wahl RL. Lung toxicity in radioiodine therapy of thyroid carcinoma: development of a dose-rate method and dosimetric implications of the $80-\mathrm{mCi}$ rule. J Nucl Med. 2006;47(12):1977-1984

38. Hobbs RF, Wahl RL, Lodge MA, et al. 124I PET-based 3D-RD dosimetry for a pediatric thyroid cancer patient: real-time treatment planning and methodologic comparison. J Nucl Med. 2009;50(11):1844-1847.

39. Song H, He B, Prideaux A, et al. Lung dosimetry for radioiodine treatment planning in the case of diffuse lung metastases. $\mathrm{J} \mathrm{Nucl} \mathrm{Med}$. 2006;47(12):1985-1994.

40. Verburg FA, Reiners C, Hanscheid H. Approach to the patient: role of dosimetric RAI Rx in children with DTC. J Clin Endocrinol Metab. 2013; 98(10):3912-3919.

41. Luster M, Clarke SE, Dietlein M, et al; European Association of Nuclear Medicine (EANM). Guidelines for radioiodine therapy of differentiated thyroid cancer. Eur J Nucl Med Mol Imaging. 2008;35(10): 1941-1959.

42. Pacini F, Schlumberger M, Dralle H, Elisei R, Smit JW, Wiersinga W; European Thyroid Cancer Taskforce. European consensus for the management of patients with differentiated thyroid carcinoma of the follicular epithelium. Eur J Endocrinol. 2006;154(6):787-803.

43. Cooper DS, Doherty GM, Haugen BR, et al. Revised American Thyroid Association management guidelines for patients with thyroid nodules and differentiated thyroid cancer. Thyroid. 2009;19(11):1167-1214.

44. Vrachimis A, Riemann B, Mader U, Reiners C, Verburg FA. Endogenous TSH levels at the time of 131I ablation do not influence ablation success, recurrence-free survival or differentiated thyroid cancer-related mortality. Eur J Nucl Med Mol Imaging. Epub 2015 Oct 23.

45. Luster M, Felbinger R, Dietlein M, Reiners C. Thyroid hormone withdrawal in patients with differentiated thyroid carcinoma: a one hundred thirty-patient pilot survey on consequences of hypothyroidism and a pharmacoeconomic comparison to recombinant thyrotropin administration. Thyroid. 2005;15(10):1147-1155.

46. Dow KH, Ferrell BR, Anello C. Quality-of-life changes in patients with thyroid cancer after withdrawal of thyroid hormone therapy. Thyroid. 1997;7(4):613-619.

47. Schroeder PR, Haugen BR, Pacini F, et al. A comparison of short-term changes in health-related quality of life in thyroid carcinoma patients undergoing diagnostic evaluation with recombinant human thyrotropin compared with thyroid hormone withdrawal. J Clin Endocrinol Metab. 2006;91(3):878-884.

48. Rosario PW, Borges MA, Purisch S. Preparation with recombinant human thyroid-stimulating hormone for thyroid remnant ablation with $131 \mathrm{I}$ is associated with lowered radiotoxicity. J Nucl Med. 2008;49(11): 1776-1782.

49. Frigo A, Dardano A, Danese E, et al. Chromosome translocation frequency after radioiodine thyroid remnant ablation: a comparison between recombinant human thyrotropin stimulation and prolonged levothyroxine withdrawal. J Clin Endocrinol Metab. 2009;94(9):3472-3476. 
50. Haugen BR, Pacini F, Reiners C, et al. A comparison of recombinant human thyrotropin and thyroid hormone withdrawal for the detection of thyroid remnant or cancer. J Clin Endocrinol Metab. 1999; 84(11):3877-3885.

51. Pacini F, Ladenson PW, Schlumberger M, et al. Radioiodine ablation of thyroid remnants after preparation with recombinant human thyrotropin in differentiated thyroid carcinoma: results of an international, randomized, controlled study. J Clin Endocrinol Metab. 2006;91(3):926-932.

52. Schlumberger M, Catargi B, Borget I, et al. Strategies of radioiodine ablation in patients with low-risk thyroid cancer. N Engl J Med. 2012; 366(18):1663-1673.

53. Mallick U, Harmer C, Yap B, et al. Ablation with low-dose radioiodine and thyrotropin alfa in thyroid cancer. $N$ Engl J Med. 2012;366(18): 1674-1685.

54. Goslings BM. Proceedings: effect of a low iodine diet on 131-I therapy in follicular thyroid carcinomata. J Endocrinol. 1975;64(3):30P.

55. Maxon HR, Thomas SR, Boehringer A, et al. Low iodine diet in I-131 ablation of thyroid remnants. Clin Nucl Med. 1983;8(3):123-126.

56. Park JT, Hennessey JV. Two-week low iodine diet is necessary for adequate outpatient preparation for radioiodine rhTSH scanning in patients taking levothyroxine. Thyroid. 2004;14:57-63.

57. Pluijmen MJ, Eustatia-Rutten C, Goslings BM, et al. Effects of lowiodide diet on postsurgical radioiodide ablation therapy in patients with differentiated thyroid carcinoma. Clin Endocrinol (Oxf). 2003;58(4): $428-435$.

58. Sonenberg M. Low-iodine diet in the treatment of differentiated thyroid cancer with radioactive iodine. Endocrine. 2002;17(2):141-143.

59. Bohuslavizki KH, Klutmann S, Jenicke L, et al. Salivary gland protection by S-2-(3-aminopropylamino)-ethylphosphorothioic acid (amifostine) in high-dose radioiodine treatment: results obtained in a rabbit animal model and in a double-blind multi-arm trial. Cancer Biother Radiopharm. 1999;14(5):337-347.

60. Kim SJ, Choi HY, Kim IJ, et al. Limited cytoprotective effects of amifostine in high-dose radioactive iodine 131-treated well-differentiated thyroid cancer patients: analysis of quantitative salivary scan. Thyroid. 2008;18(3):325-331.

61. Jentzen W, Balschuweit D, Schmitz J, et al. The influence of saliva flow stimulation on the absorbed radiation dose to the salivary glands during radioiodine therapy of thyroid cancer using 124I PET(/CT) imaging. Eur J Nucl Med Mol Imaging. 2010;37(12):2298-2306.

62. Nakada K, Ishibashi T, Takei T, et al. Does lemon candy decrease salivary gland damage after radioiodine therapy for thyroid cancer? J Nucl Med. 2005;46(2):261-266.

63. Wiersinga WM, Duntas L, Fadeyev V, Nygaard B, Vanderpump MP. 2012 ETA guidelines: the use of L-T4 + L-T3 in the treatment of hypothyroidism. Eur Thyroid J. 2012;1(2):55-71.

64. McLeod DS, Cooper DS, Ladenson PW, et al; The National Thyroid Cancer Treatment Cooperative Study Group SI. Prognosis of differentiated thyroid cancer in relation to serum thyrotropin and thyroglobulin antibody status at time of diagnosis. Thyroid. 2014;24(1):35-42.

65. Smit JW, Eustatia-Rutten CF, Corssmit EP, et al. Reversible diastolic dysfunction after long-term exogenous subclinical hyperthyroidism: a randomized, placebo-controlled study. J Clin Endocrinol Metab. 2005;90(11):6041-6047.

66. Selmer C, Olesen JB, Hansen ML, et al. The spectrum of thyroid disease and risk of new onset atrial fibrillation: a large population cohort study. BMJ. 2012;345:e7895.

67. Chaker L, Heeringa J, Dehghan A, et al. Normal thyroid function and the risk of atrial fibrillation: the rotterdam study. J Clin Endocrinol Metab. 2015;100(10):3718-3724.

68. Hovens GC, Stokkel MP, Kievit J, et al. Associations of serum thyrotropin concentrations with recurrence and death in differentiated thyroid cancer. J Clin Endocrinol Metab. 2007;92(7):2610-2615.

69. Cooper DS, Specker B, Ho M, et al. Thyrotropin suppression and disease progression in patients with differentiated thyroid cancer: results from the National thyroid cancer treatment cooperative registry. Thyroid. 1998;8(9):737-744.
70. Diessl S, Holzberger B, Mader U, et al. Impact of moderate vs stringent TSH suppression on survival in advanced differentiated thyroid carcinoma. Clin Endocrinol (Oxf). 2012;76(4):586-592.

71. Biko J, Reiners C, Kreissl MC, Verburg FA, Demidchik Y, Drozd V. Favourable course of disease after incomplete remission on (131)I therapy in children with pulmonary metastases of papillary thyroid carcinoma: 10 years follow-up. Eur J Nucl Med Mol Imaging. 2011;38(4): 651-655.

72. Clement SC, Peeters RP, Ronckers CM, et al. Intermediate and longterm adverse effects of radioiodine therapy for differentiated thyroid carcinoma - a systematic review. Cancer Treat Rev. 2015;41(10): 925-934.

73. Hay ID, Bergstralh EJ, Grant CS, et al. Impact of primary surgery on outcome in 300 patients with pathologic tumor-node-metastasis stage III papillary thyroid carcinoma treated at one institution from 1940 through 1989. Surgery. 1999;126(6):1173-1181.

74. Sawka AM, Thabane L, Parlea L, et al. Second primary malignancy risk after radioactive iodine treatment for thyroid cancer: a systematic review and meta-analysis. Thyroid. 2009;19(5):451-457.

75. Verkooijen RB, Smit JW, Romijn JA, Stokkel MP. The incidence of second primary tumors in thyroid cancer patients is increased, but not related to treatment of thyroid cancer. Eur J Endocrinol. 2006;155(6): 801-806.

76. Alexander C, Bader JB, Schaefer A, Finke C, Kirsch CM. Intermediate and long-term side effects of high-dose radioiodine therapy for thyroid carcinoma. J Nucl Med. 1998;39(9):1551-1554.

77. Solans R, Bosch JA, Galofre P, et al. Salivary and lacrimal gland dysfunction (sicca syndrome) after radioiodine therapy. J Nucl Med. 2001; 42(5):738-743.

78. Van Nostrand D. Sialoadenitis secondary to ${ }^{131} \mathrm{I}$ therapy for welldifferentiated thyroid cancer. Oral Dis. 2011;17(2):154-161.

79. Dottorini ME, Vignati A, Mazzucchelli L, Lomuscio G, Colombo L. Differentiated thyroid carcinoma in children and adolescents: a 37-year experience in 85 patients. $J$ Nucl Med. 1997;38(5):669-675.

80. Seidlin SM, Siegal E, Yalow AA, Melamed S. Acute myeloid leukemia following prolonged iodine-131 therapy for metastatic thyroid carcinoma. Science. 1956;123(3201):800-801.

81. Subramanian S, Goldstein DP, Parlea L, et al. Second primary malignancy risk in thyroid cancer survivors: a systematic review and metaanalysis. Thyroid. 2007;17(12):1277-1288.

82. Iyer NG, Morris LG, Tuttle RM, Shaha AR, Ganly I. Rising incidence of second cancers in patients with low-risk (T1N0) thyroid cancer who receive radioactive iodine therapy. Cancer. 2011;117(19):4439-4446.

83. Hanscheid H, Lassmann M, Luster M, Kloos RT, Reiners C. Blood dosimetry from a single measurement of the whole body radioiodine retention in patients with differentiated thyroid carcinoma. Endocr Relat Cancer. 2009;16(4):1283-1289.

84. Verburg FA, Lassmann M, Mader U, Luster M, Reiners C, Hanscheid H. The absorbed dose to the blood is a better predictor of ablation success than the administered $131 \mathrm{I}$ activity in thyroid cancer patients. Eur $J$ Nucl Med Mol Imaging. 2011;38(4):673-680.

85. Hanscheid H, Verburg FA, Biko J, et al. Success of the postoperative (131)I therapy in young Belarusian patients with differentiated thyroid cancer after Chernobyl depends on the radiation absorbed dose to the blood and the thyroglobulin level. Eur J Nucl Med Mol Imaging. 2011;38(7):1296-1302.

86. Durante C, Haddy N, Baudin E, Leboulleux S, et al. Long-term outcome of 444 patients with distant metastases from papillary and follicular thyroid carcinoma: benefits and limits of radioiodine therapy. J Clin Endocrinol Metab. 2006;91(8):2892-2899.

87. Verburg FA, Mader U, Kruitwagen CL, Luster M, Reiners C. A comparison of prognostic classification systems for differentiated thyroid carcinoma. Clin Endocrinol (Oxf). 2010;72(6):830-838.

88. Brierley JD, Panzarella T, Tsang RW, Gospodarowicz MK, O'Sullivan B. A comparison of different staging systems predictability of patient outcome. Thyroid carcinoma as an example. Cancer. 1997;79(12):2414-2423. 
89. Tuttle RM, Tala H, Shah J, et al. Estimating risk of recurrence in differentiated thyroid cancer after total thyroidectomy and radioactive iodine remnant ablation: using response to therapy variables to modify the initial risk estimates predicted by the new american thyroid association staging system. Thyroid. 2010;20(12):1341-1349.

90. Blum M, Tiu S, Chu M, Goel S, Friedman K. I-131 SPECT/CT elucidates cryptic findings on planar whole-body scans and can reduce needless therapy with I-131 in post-thyroidectomy thyroid cancer patients. Thyroid. 2011;21(11):1235-1247.
91. Verburg FA, Stokkel MP, Duren C, et al. No survival difference after successful (131)I ablation between patients with initially low-risk and high-risk differentiated thyroid cancer. Eur J Nucl Med Mol Imaging. 2010;37(2):276-283.

\section{Publish your work in this journal}

OncoTargets and Therapy is an international, peer-reviewed, open access journal focusing on the pathological basis of all cancers, potential targets for therapy and treatment protocols employed to improve the management of cancer patients. The journal also focuses on the impact of management programs and new therapeutic agents and protocols on

\section{Dovepress}

patient perspectives such as quality of life, adherence and satisfaction. The manuscript management system is completely online and includes a very quick and fair peer-review system, which is all easy to use. Visit http://www.dovepress.com/testimonials.php to read real quotes from published authors.

Submit your manuscript here: http://www.dovepress.com/oncotargets-and-therapy-journal 